\title{
Differences Between Generalists and Specialists
}

\author{
Knowledge, Realism, or Primum Non Nocere?
}

A ccording to Paul Starr's classic treatise, The Social Transformation of American Medicine, the rivalry among physician groups has its roots more than one hundred years ago. ${ }^{1}$ In the $19^{\text {th }}$ century, allopathic and homeopathic physicians each touted their own skills when competing for patients. In the Boston Medical and Surgical Journal in 1851, Edward Warren (an allopath) used heated words to describe homeopathic physicians who 'deluded' themselves by prescribing medications that were 'absurd'. ${ }^{2}$ Two articles in this issue of the Journal of General Internal Medicine (JGIM) continue the scrutiny of physician prescribing practices, but employ levelheaded evidence rather than the emotional terms of centuries past.

Stone et al. presented 2,438 internists and infectious disease specialists with two hypothetical HIV-infected patients. ${ }^{3}$ From 1,062 responses, they found that both physician specialty and HIV experience, as measured by the number of patients treated presently and over the career, were independently associated with recommending antiretroviral treatment that met contemporary expert guidelines. Consistent with these findings, others have observed a survival advantage for patients who have more experienced providers. ${ }^{4,5}$ Not accounting for HIV experience, more favorable hospitalization outcomes have been shown for patients with AIDS under the care of infectious disease (or hematology/oncology) physicians compared with generalists' patients. ${ }^{6}$ However, in the study by Stone et al., generalists were significantly less likely than infectious disease physicians to prescribe appropriate therapy at each level of HIV experience. These survey data add worrisome evidence that even with plenty of clinical experience in a specialty, generalists' knowledge may lag behind. Fortunately, generalists often indicated they would consult a specialist when confronted with patients such as those in the study scenarios, suggesting that they realize their limitations and would share care appropriately.

Yet there is a twist to Stone et al.'s story. Although the second hypothetical patient should have been offered treatment according to guidelines in effect at the time of the survey, ${ }^{7,8}$ recently revised guidelines recommend holding off on treating a patient with these laboratory and clinical characteristics. ${ }^{9}$ So who's right? Perhaps generalists were appropriately cautious because HIV guidelines are "living documents" that undergo frequent modifications. ${ }^{9}$ Alternately, generalists might have been more realistic about a patient's ability to take drugs with significant potential toxicities and that require adhering to a demanding dosing schedule. Concern about the feasibility of guideline-based practice may contribute to the discord between what the guidelines say and what generalists do.
Also in this issue, Majumdar et al. ${ }^{10}$ examined use of medications in patients hospitalized for acute myocardial infarction both before and after widely publicized reports of the adverse effects of calcium channel blockers were released. ${ }^{11,12}$ Majumdar et al. reported that generalists and cardiologists were equally likely to avoid calcium channel blockers after these reports. Generalists were also equally likely to drop lidocaine use after its risks became evident. On the other hand, generalists were less likely to adopt effective myocardial infarction therapies, particularly thrombolytic agents, with potentially serious side effects. However, patients managed jointly by a generalist and a cardiologist were more likely to have received beneficial therapies. Therefore, both of these studies in this issue raise the appealing option of shared care for patients with complex conditions.

Majundar et al. hypothesized that contradictory patterns of rapidly relinquishing some drugs while failing to adopt others were partly related to generalists being risk averse. Ayanian et al. previously proposed the theory of risk aversion when they also found that generalists had lower rates of using aspirin, beta blockers, and thrombolytic therapy in patients with acute myocardial infarction. ${ }^{13}$ Yet, contrary to Majumdar et al.'s observations, Ayanian found that generalists were more likely to use calcium channel blockers and lidocaine and speculated that both generalists' risk aversion and lack of knowledge were at play. In a study of $H$. pylori infection-related practices, Fendrick et al. postulated that generalists' "wait and see attitude" stems from worries about complications or conservatism about changing established patterns of care. ${ }^{14}$ Based on a study of decision making about prescription of postmenopausal hormone replacement therapy, Elstein et al. observed that physicians made decisions to minimize the most important risk regardless of its probability. ${ }^{15}$ Although that study did not compare generalists and specialists, it does suggest that risk aversion is a powerful force in clinical decision making.

Specialists may seem less risk averse than generalists because they are more accurate in estimating the risks and benefits of therapies in their field or have better access to sound data sources on which to base therapeutic decisions. Peay and Peay reported that specialists depended primarily on professional sources of information such as journals and medical meetings for risky therapies and on drug detail people or other commercial sources for moderate or low risk therapies. ${ }^{16}$ They also reported that specialists relied less on commercial sources of information than did generalists. Following this line of evidence, it is possible that generalists who primarily use commercial sources of information might be more skeptical about adopting a relatively risky new therapy. Yet, generalists 
are hardly a homogeneous group. Peay and Peay found that hospital-based generalists gave higher ratings to journals and pharmacists as sources of information than did community-based physicians. ${ }^{16}$ Similarly, Chin et al. found that generalists and specialists at an urban academic center did not differ in prescribing ACE inhibitors for patients with reduced ejection fractions, ${ }^{17}$ while a similar study including generalists in the community did show a difference. ${ }^{18}$ Academically-based generalists may benefit from greater exposure to continuing education on therapeutic advances, closer interactions with subspecialty colleagues permitting informal sharing of new advances, or themselves become experts in a field.

The articles in this issue of JGIM add to reams of papers reporting that specialists have the edge when it comes to current knowledge in their area of expertise. A recent review summarizes these studies nicely. ${ }^{19}$ However, evidence regarding the advantages of specialist management in regard to patient outcomes and cost of care is more sparse. ${ }^{20,21}$ In addition, most studies do not evaluate specialists' practices outside their comfortable area of expertise. Cardiology and pulmonary specialists were found to be less informed about breast cancer screening guidelines than generalists ${ }^{22}$ and HIV-infected patients whose usual source of care was a specialist were more likely to resort to the emergency room for urgent care than generalists' patients. $^{23}$ These data suggest that patients who use a specialist as their usual source of care may experience poorer outcomes when they seek preventive and/or urgent care.

These papers on the generalist-specialist debate add more worries about generalists' abilities to adopt new advances and shed outdated practices but also raise many questions to pursue in the future. Are generalists realistically cautious about innovations or just ill-informed? What can be done to help generalists more accurately assess the risks and benefits of therapeutic advances? Is the model of shared generalist-specialist care the answer to this dilemma? If so, how can we accomplish this in a health care environment that may penalize generalists for specialty referrals? What is the role of increasingly well-informed patient preferences? The balance and interplay of knowledge, realism, and primum non nocere promises to challenge both generalists and specialists in the years to come.

- Barbara J. Turner MD, MSEd, Division of General Internal Medicine, Department of Medicine, University of Pennsylvania School of Medicine, Philadelphia, Pa, and Christine LAINe MD, MPH, Division of Internal Medicine and Center for Research in Medical Education and Health Care, Jefferson Medical College, Thomas Jefferson University, Philadelphia, Pa.

\section{REFERENCES}

1. Starr P. The consolidation of authority 1850-1930. In: Starr P, ed. The Social Transformation of American Medicine. New York, NY: Basic Books, Inc.; 1949:97.
2. Warren E. Homæopathy. Boston Med Surg J. 1851;12:234-7.

3. Stone VE, Mansourati FF, Poses RM, Mayer KH. Relation of physician specialty and HIV/AIDS experiences to choice of guidelinerecommended antiretroviral therapy. J Gen Intern Med. 2001;16: 360-8.

4. Kitahata MM, Koepsell TD, Deyo RA, Maxwell CL, Dodge WT, Wagner EH. Physicians' experience with the acquired immunodeficiency syndrome as a factor in patients' survival. N Engl J Med. 1996;334:701-6.

5. Laine C, Markson LE, McKee LJ, Hauck WW, Fanning TR, Turner BJ. The relationship of clinic experience with advanced HIV and survival of women with AIDS. AIDS. 1998;12:417-24.

6. Turner BJ, McKee L, Fanning T, Markson LE. AIDS specialist versus generalist ambulatory care for advanced HIV infection and impact on hospital use. Med Care. 1994;32:902-16.

7. Fauci AS, Bartlett JG, and the Panel on Clinical Practices for Treatment of HIV Infection. Panel on Clinical Practices for Treatment of HIV Infection. Guidelines for the use of antiretroviral agents in HIV-infected adults and adolescents. Department of Health and Human Services. Office of Public Health and Science. 1997. Federal Register Doc \# 97-16228.

8. Carpenter CCJ, Fischl MA, Hammer SM, et al. Antiretroviral Therapy for HIV Infection in 1997: updated recommendations of the International AIDS Society - USA Panel. JAMA. 1997;277: 1962-9.

9. Fauci AS, Bartlett JG, Goosby EP, Kates J, and the Panel on Clinical Practices for the Treatment of HIV Infection convened by the Department of Health and Human Services (DHHS) and the Henry J. Kaiser Family Foundation. Guidelines for the use of antiretroviral agents in HIV-infected adults and adolescents (February 5, 2001). Available at http://www.hivatis.org.

10. Majumdar SR, Inui TS, Gurwitz JH, Gillman MW, McLaughlin TJ, Soumerai SB. Influence of physician specialty on adoption and relinquishment of calcium channel blockers and other treatments for myocardial infarction. J Gen Intern Med. 2001;16:351-9.

11. Psaty BM, Heckbert SR, Koepsell TD, et al. The risk of incident myocardial infarction associated with antihypertensive drug therapies (abstract). Circulation. 1995;91:925.

12. Psaty BM, Heckbert SR, Koepsell TD, et al. The risk of myocardial infarction associated with antihypertensive drug therapies. JAMA. 1995;274:620-5.

13. Ayanian J, Hauptman PJ, Guadagnoli E, Antman EM, Pashos CL, McNeil BJ. Knowledge and practices of generalist and specialist physicians regarding drug therapy for acute myocardial infarction. New Engl J Med. 1994;331:1136-42.

14. Fendrick AM, Hirth RA, Chernew ME. Differences between generalist and specialist physicans regarding Helicobacter pylori and peptic ulcer disease. Am J Gastroenterol. 1996;91:1544-8.

15. Elstein AS, Holzman GB, Ravitch MM, et al. Comparison of physicians' decisions regarding estrogen replacement therapy for menopausal women and decisions derived from a decision analytic model. Am J Med. 1986;80:246-58.

16. Peay MY, Peay ER. Patterns of preference for information sources in the adoption of new drugs by specialists. Soc Sci Med. 1990; 31:467-76.

17. Chin MH, Wang JC, Zhang JX, Lang RM. Utilization and dosing of angiotensin-converting enzyme inhibitors for heart failure: effect of physician specialty and patient characteristics. J Gen Intern Med. 1997;12:563-6.

18. Chin MH, Friedmann PD, Cassel CK, Lang RM. Differences in generalist and specialist physicians' knowledge and use of angiotensin-converting enzyme inhibitors for congestive heart failure. J Gen Intern Med. 1997;12:523-30.

19. Harrold LR, Field TS, Gurwitz JH. Knowledge, patterns of care, and outcomes of care for generalists and specialists. J Gen Intern Med. 1999; 14:499-511.

20. Donohoe MT. Comparing generalist and specialty care. Arch Intern Med. 1998;158:1596-1608. 
21. Greenfield S, Nelson EC, Zubkoff M, et al. Variations in resource utilization among medical specialties and systems of care. JAMA. 1992;267:1624-30.

22. Turner BJ, Amsel Z, Lustbader E, Schwartz JS, Balshem A, Grisso JA. Breast cancer screening: impact of physician specialty, practice setting, year of medical school graduation, and sex. Am J Prev Med. 1992;8:78-85.

23. Mauskopf J, Turner BJ, Markson LE, Houchens RL, Fanning TR, McKee L. Patterns of ambulatory care for AIDS patients and association with emergency room use. Health Serv Res. 1994;29:489-510. 